\section{Entre mundos: a trajetória de jovens de baixa renda}

\author{
Letícia Couto Bicalho* \\ Wânia Maria Araújo** \\ Vanessa Belisário***
}

\begin{abstract}
Resumo
O trabalho em comento discute a entrada de jovens de camadas populares no sistema de educação superior, destacando três momentos distintos vividos por eles, sendo o primeiro, no final do ensino médio, quando buscam uma alternativa para se prepararem para o vestibular; o segundo, quando são aprovados e ingressam em uma universidade pública; e o terceiro, quando buscam a inserção no mercado de trabalho, após terem concluído a graduação. Com isso, pretende-se pesquisar os fatores que embasam a atitude positiva desses jovens, a despeito de suas condições originais adversas. A pesquisa qualitativa foi eleita como o procedimento metodológico e o instrumento de coleta de dados será a entrevista realizada com dois estudantes que trilharam por esse caminho.
\end{abstract}

Palavras-chave: Educação. Jovens de Camadas Populares. Motivação Juvenil.
* Mestrado em Gestão Social, Educação e Desenvolvimento Local, pela UNA.

\footnotetext{
** Doutora em Ciências Sociais pela PUC Minas. Docente na UNA.
}

*** Mestrado em Gestão Social, Educação e Desenvolvimento Local, pela UNA. oportunidade de pertencer a uma universidade federal e
trabalhar com jovens de camadas populares me fez, com o
passar dos anos, voltar o olhar atento para as etapas da vida de muitos deles, com os quais pude conversar, indagar e acompanhar a caminhada de preparação para o ingresso no curso superior desejado e sua posterior permanência até a conclusão do mesmo, almejando o acesso ao mercado profissionalizante.

Nesse sentido, este trabalho discute a entrada de jovens de camadas populares no ensino superior e destaca três contextos distintos: o primeiro, no final do ensino médio, quando estão em busca de uma forma alternativa de preparação para o vestibular e se deparam com as expectativas do momento vivido e com os receios em relação a um futuro incerto; o segundo, quando já estão aprovados em curso superior, em uma universidade pública, e se veem confrontados com seus anseios e dilemas; e o terceiro, quando concluída a etapa de graduação, lutam para serem aceitos no mercado de trabalho.

A busca por elucidações acerca desses três momentos vividos por esses jovens justifica-se por se perceber a existência de conflitos e estranhamentos frente a essa nova realidade. Por isso, a pergunta que se faz é: Qual o diferencial desses sujeitos que, mesmo apresentando uma situação socioeconômica 
e cultural vulnerável, conseguem trilhar esse caminho e ingressarem em uma instituição de ensino superior pública? O interesse por descortinar e compreender essa questão foi o que mobilizou a busca e a tentativa de interpretar da trajetória de sujeitos. Terão eles uma motivação externa, familiar ou social? Terão uma capacidade de resiliência que os tornam mais resistentes às adversidades e mais criativos para enfrentá-las?

"Ao projetar uma situação no futuro, estão implicados tanto o seu passado como o momento presente enquanto trajetórias individuais, mas também os percalços apresentados pelo modelo produtivo vigente a serem vencidos" (D'AVILA et al., 2011, p. 8).Tendo em conta essa afirmação, pretendese pesquisar quais os fatores que caracterizam a atitude positiva desses jovens estudantes a despeito de suas condições originais adversas e, para uma melhor compreensão dessa questão, tem-se em mente a explicação de Lima (1993, p.170): "As atitudes não nascem num vazio social, mas pelo contrário, são fruto da interação social, de processos de corporação, identificação e diferenciação sociais que nos permitem situar a nossa posição face à de outros num determinado momento do tempo".

Neste trabalho, vamos nos ater aos jovens que buscaram um curso prévestibular popular, de uma universidade pública, para se prepararem e, quando aprovados no curso por eles escolhido, puderam traçar novos caminhos diante dessa nova realidade.

Como aporte teórico para a discussão aqui apresentada, serão consideradas as reflexões dos seguintes autores: Piotto (2008), Whitaker e Onofre (2006; 2010), Lahire (1997; 2011) e D'Avila et al., (2011) por trazerem ideias pertinentes em relação às possíveis interconexões do sucesso escolar de jovens de camadas populares com elementos subjetivos de sua formação, estabelecendo um paralelo com entrevistas realizadas com dois jovens de baixa renda que se prepararam para o vestibular, neste curso popular específico, e hoje são alunos do nível superior, em uma universidade pública.

Considera-se subjetividade como "[...] a organização dos processos de sentido e significação que aparecem e se organizam de diferentes formas e em diferentes níveis no sujeito e na personalidade, assim como nos diferentes espaços sociais em que o sujeito atua" (REY, 1999, p. 108). Ela pode apresentarse em dois níveis: o individual e o social. Assim, para melhor situar a trajetória dos dois jovens escolhidos para a entrevista que complementa esta pesquisa, é preciso refletir sobre o processo vivenciado até a conclusão do ensino médio e a opção de vida pela continuidade dos estudos, considerando suas dificuldades e suas condições fragilidade econômica e social.
1 Esta é a agência líder da rede global de desenvolvimento da ONU e trabalha principalmente pelo combate à pobreza e pelo desenvolvimento humano, dando origem ao IDH (Índice de Desenvolvimento Humano). Faz parcerias com pessoas em todas as instâncias da sociedade para ajudar na construção de nações que possam resistir a crises.

2 Embora o nome correto seja Curso Pré-Universitário Popular da Universidade Federal de Juiz de Fora, iremos citá-lo como curso pré-vestibular ou cursinho, referências popularmente conhecidas, dando clareza à sua proposta que é preparar os alunos para o vestibular ou para qualquer outra forma de seleção para o acesso ao ensino superior

Revista @rquivo Brasileiro de Educação, Belo Horizonte, vol.1, num.2, jul - dez, 2013. 


\section{Reflexões sobre a trajetória educacional de jovens de camadas populares}

O Brasil tem apresentado progresso em relação aos investimentos em educação e são inegáveis as oportunidades que estão sendo oferecidas aos jovens para o ingresso em instituições de ensino superior. Para ilustrar, temos o SISU (Sistema de Seleção Unificada), o PROUNI (Programa Universidade para Todos), e o FIES (Fundo de Financiamento Estudantil). Contudo, a dívida histórica com a educação ainda é traduzida por altos níveis de repetência, evasão, analfabetismo e, principalmente, pela distorção série/idade. (INSTITUTO BRASILEIRO DE GEOGRAFIA E ESTATÍSTICA, 2013).

A Pesquisa realizada em 2013 pelo PNUD ${ }^{1}$ (Programa das Nações Unidas para o Desenvolvimento), mostrou que jovens de 15 a 17 anos com ensino fundamental completo passaram de $20 \%$ para $57,2 \%$, porém, $40 \%$ dos estudantes nessa faixa etária ainda não concluíram essa formação. Jovens de 18 a 20, anos com ensino médio completo, passaram de $13 \%$ para $41 \%$, ou seja, a maioria deles (59\%) ainda não possui o ensino médio completo (PROGRAMA DAS NAÇÕES UNIDAS PARA O DESENVOLVIMENTO, 2013).

O IPEA (Instituto de Pesquisa Econômica Aplicada), afirma ser a falta de instrução o principal problema enfrentado pela juventude. "Sem acesso a um sistema educacional eficiente, ela (a juventude) sofre com a escassez de oportunidades no mercado de trabalho e com o aumento da violência" (CORBUCCI, 2011).

Se por um lado a falta de oportunidade de acesso à educação para a população jovem constitui um desafio aos anseios desse segmento, por outro, aqueles que concluem o ensino médio parecem ter alcançado um estágio de sucesso, caso consideremos a baixa porcentagem de concluintes.

Para Marco Antônio Raupp, presidente da SBPC (Sociedade Brasileira para o Progresso da Ciência), o Brasil apresenta um imenso déficit na educação básica, que contempla os níveis de ensino fundamental e médio, e a solução definitiva dos problemas apresenta duas ordens de desafios: uma, que exige resultados urgentes; outra, que proporcione mudanças estruturais no sistema educacional e que apresente resultados no médio e longo prazo. A primeira ordem de desafios se refere aos problemas gritantes do sistema de ensino brasileiro, como a formação de analfabetos funcionais (pessoas que não entendem o que leem) e, em segunda ordem, a carência de professores

Revista @rquivo Brasileiro de Educação, Belo Horizonte, vol.1, num.2, jul - dez, 2013. 
e a recuperação da importância da escola na vida das comunidades (RAUPP apud EDUCAÇÃO..., 2010, p. 1)

Percebe-se que, cada vez mais, as exigências recaem sobre os jovens no sentido de que eles se preparem para a profissionalização. No caso brasileiro, esse tipo de preparação se restringe à inserção nos cursos superiores, e, em particular, à entrada da pessoa em condições de pobreza e/ou vulnerabilidade social, o que tem se constituído num complicador a mais (BONETI, 2008), dada às desvantagens que esses alunos enfrentam ao competirem com aqueles que tiveram um percurso diferenciado, ou estudarem em escolas cuja qualidade do ensino de destacava em relação ás demais.

Ainda assim, rompendo com os percalços e evidenciando problemas como falta de recursos, desmotivação, cansaço causado pela dupla jornada trabalho-escola e baixo desempenho escolar, uma parcela de jovens consegue concluir o ensino médio e almejar a continuidade dos estudos.

Os cursos pré-vestibulares populares surgem como uma alternativa, já que eles representam uma conquista das classes subalternas e a possibilidade de acesso a uma preparação que, até então, era exclusiva dos jovens das classes favorecidas.

\section{O Curso Pré-Universitário Popular da Universidade Federal de Juiz de Fora}

A UFJF (Universidade Federal de Juiz de Fora) foi criada em 1960 e é um polo acadêmico e cultural da região Zona da Mata Mineira, com pouco mais de 500 mil habitantes, a 184 quilômetros do Rio de Janeiro e a 265 quilômetros de Belo Horizonte. Sendo a cidade uma metrópole regional, ela atrai não só alunos de cidades vizinhas, mas também de outras regiões e estados.

Em 2005, a Universidade criou o Curso Pré-Universitário Popular, ${ }^{2}$ como parte integrante de uma política global de inclusão, constituindo um Projeto de Treinamento Profissional vinculado à Pró-Reitoria de Graduação (PROGRAD).

Desde então, foram atendidos mais de mil jovens oriundos de escolas públicas e de camadas populares de Juiz de Fora e entorno. São mais de 20 cidades e municípios vizinhos, representando novas conquistas para aqueles que almejam futuros mais promissores, continuidade nos estudos e oportunidades de trabalho. O cursinho surge como um meio de resgate da autoestima e sua meta é a valorização do jovem, de sua da família e, muitas vezes, da comunidade

Revista @rquivo Brasileiro de Educação, Belo Horizonte, vol.1, num.2, jul - dez, 2013. 
onde está inserido. Ressalta-se que a má formação escolar, relativa aos ensinos fundamental e médio, constitui uma barreira a exigir muitos esforços diante da aquisição tardia de competências não adquiridas ao longo do percurso escolar regular.

O cursinho é o resultado de um trabalho que visa compreender um processo dinâmico de superação de desafios e que busca alternativas pedagógicas como forma de ressignificar o processo de ensinar e de aprender.

Mas, se há uma oportunidade concreta de preparação para o enfrentamento da seleção e para o ingresso em instituições de ensino superior, há também um diferencial no sujeito que, mesmo apresentando uma situação socioeconômica e cultural vulnerável, consegue ultrapassar essas barreiras e idealizar novos projetos de vida.

\section{Resiliência e subjetividade nos jovens e a relação escolar}

Resiliência é um termo que surgiu historicamente na medicina para definir a capacidade de recuperação de pessoas expostas a algum problema sério de saúde. Utilizado também pela psicologia, o propósito seria o de evidenciar características de proteção perante situações traumáticas. Já a sociologia apoderou-se desse termo para explicar a capacidade dos indivíduos de se recuperarem diante das adversidades. Para a sociologia, a resiliência é caracterizada como um conjunto de processos que possibilitam uma vida saudável, ainda que o indivíduo viva em um meio desfavorecido (BEM, 2012, p. 47-55).

Assim, buscamos termos e designações para explicar como estudantes de camadas populares enfrentam situações adversas, com resistência e criatividade, adaptando-se aos desafios e às dificuldades que se apresentam.

Deste modo, a resiliência não pode ser pensada como um atributo com o qual os indivíduos nascem ou que é adquirido durante o seu desenvolvimento, mas como um processo que se constrói com o meio, com as relações sociais (SILVA, 2009, p. 2-11). Esta construção parece estar ligada à formação do indivíduo na medida em que a família, a escola e as relações sociais contribuem como elementos agregadores à autoestima dos jovens.

Os fatores que influenciam a resiliência nos estudantes e lhes garantem percursos de vida saudáveis, dependem do envolvimento com a família e com a escola. Eles sentem-se apoiados e incentivados pelos adultos para o

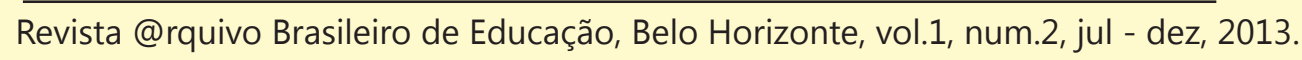


desenvolvimento e aperfeiçoamento de capacidades de tomada de decisão e resolução de problemas. Este apoio parece ser significativo para a resolução de problemas que vão surgindo no percurso da sua vida (SILVA, 2009, p. 7-11).

Nesse sentido, resiliência é a

capacidade de responder de forma mais consistente aos desafios e dificuldades, de reagir com flexibilidade e capacidade de recuperação diante desses desafios e circunstâncias desfavoráveis, tendo atitudes otimistas, positivas e perseverantes, mantendo um equilíbrio dinâmico durante e após os embates - uma característica de personalidade que, ativada e desenvolvida, possibilita ao sujeito superar-se e às pressões de seu mundo, desenvolver um autoconceito realista, autoconfiança e um senso de autoproteção, que não desconsidera a abertura ao novo, à mudança, ao outro e à realidade subjacente (TAVARES apud SILVA, 2009, p. 11).

\section{Metodologia}

Esta pesquisa é parte da minha dissertação, a ser concluída nos próximos meses. Para este artigo, foram utilizados dados de apenas duas das entrevistas realizadas e a investigação apresentada é de caráter qualitativo e se caracteriza como estudo exploratório e descritivo.

O desenho da pesquisa se estrutura na análise sistemática das reflexões de alguns autores que discutem as possíveis interconexões do sucesso escolar de jovens de camadas populares com elementos subjetivos em sua formação. Estabelece, ainda, um paralelo com as análises das entrevistas realizadas com dois jovens de baixa renda que se prepararam para o vestibular nesse curso popular e hoje cursam o nível superior em uma universidade pública.

A entrevista inclui questões referentes aos contextos vivenciados pelos dois jovens no final do ensino médio e quando já aprovados para o curso superior, destacando projetos de vida, desejos e incentivos recebidos.

Os dados aqui analisados evidenciam os fatores que embasam a atitude diferenciada desses estudantes, entretanto, não tem o propósito de esgotar o assunto, mas sim o de trazer contribuições que sejam elucidativas e elementos que auxiliem a interpretação do sucesso escolar nas camadas populares.

Revista @rquivo Brasileiro de Educação, Belo Horizonte, vol.1, num.2, jul - dez, 2013. 


\section{Analisando e interpretando os dados}

Osjovens ${ }^{3}$ entrevistados, Ana e William, têm 21 e 22 anos respectivamente. Ambos estudam na Universidade Federal de Juiz de Fora, porém em áreas diferentes de formação: um é das ciências humanas e outro da área da saúde. William trabalha em horário integral e Ana, somente em meio horário. Eles são oriundos de escolas públicas estaduais e residem na cidade de Juiz de Fora. Cursaram o pré-vestibular popular da UFJF e foram bem classificados no processo seletivo para o curso superior.

De certa forma, podemos considerá-los privilegiados tanto por fazerem parte de uma estatística positiva quanto à conclusão do ensino médio, quanto por terem tido a oportunidade de participar de um curso preparatório popular, com chances reais de sucesso. Em seus relatos, os dois estudantes especificaram as dificuldades ocorridas durante a passagem do ensino médio para a universidade e alegaram ter procurado o cursinho pela qualidade e gratuidade: "Eu não tinha dinheiro para pagar um cursinho e tive sorte de encontrar um cursinho popular". (William).

Para Whitaker e Onofre (2006), "o fenômeno vestibulares é um dos mais importantes rituais de passagem que marca o fim da adolescência e introduz parte da juventude nos espaços privilegiados da universidade" (WHITAKER; ONOFRE, 2006, p.2).

Mas, apesar da existência desse ritual, Whitaker salienta que "A dificuldade do estudante brasileiro em relação à entrada na universidade e especificamente os filhos das famílias de baixa renda são decorrentes da fraqueza de capital cultural". (WHITAKER; ONOFRE, 2010. p. 2). Sobre a necessidade em frequentar cursinhos, a autora afirma que: "[...] o cursinho é como se fosse um degrau inserido no sistema escolar. A ninguém ocorreu lembrar que o cursinho não faz parte do sistema e significa uma estratégia para-escolar para ajudar a tornar o estudante mais competitivo no momento da seleção" (WHITAKER; ONOFRE, 2006. p. 5).

O bom ou mau desempenho escolar não estão necessariamente ligados às condições socioeconômicas do aluno, demonstrando que existem elementos culturais mais amplos para explicar o sucesso ou o fracasso escolar. (LAHIRE, 1997, p. 13-22).

Quando foram indagados sobre seus projetos de vida, antes da entrada no pré-vestibular popular, Ana afirmou ter um propósito firme de cursar o ensino superior, já Willian pretendia cursar o ensino universitário aliado ao

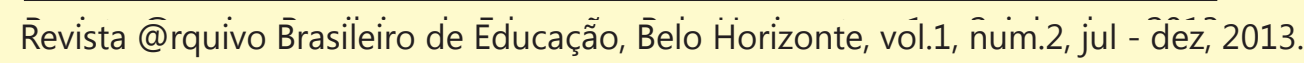


trabalho, diante da necessidade de garantir sua subsistência.

"Me dediquei muito no cursinho. Eu queria passar no vestibular de qualquer jeito [...]". (William).

"Eu não pensava em outra coisa [...] me via dentro da universidade, só ficava imaginando como seria legal! (Ana)".

Sobre seus projetos após a entrada no curso pretendido, ambos estavam animados em relação aos sonhos e objetivos, mas também apresentaram preocupações quanto à conclusão do ensino superior e a entrada no mercado de trabalho. E acrescentaram: [...] Eu passei no vestibular, arrumei um emprego como promotor de vendas em supermercados e, depois de um tempo, comprei a minha moto [...] sorriu! (William).

[...] Por existir a Universidade Federal em Juiz de Fora, parece que o jovem aqui é mais estimulado [...] todos querem fazer Federal! Estou fazendo o curso que eu sempre quis. Estou confiante que vai dar tudo certo. (Ana).

Percebe-se que há o estabelecimento de um caminho traçado pelo jovem, o que podemos denominar projeto de vida, que é específico a cada um. Sobre isso, D'Avila et al $(2011$, p. 3) afirmam que a definição de um projeto de vida implica na escolha do que se deseja ser, ou mesmo do que se deseja realizar no mundo, e que o futuro possui certa previsibilidade quando o sujeito analisa suas condições de vida e lança as suas possibilidades.

As discussões de Piotto (2008) compreendem as condições que possibilitam trajetórias prolongadas nas camadas populares, investigando, além do acesso, sua permanência no ensino superior. A autora enfatiza que pesquisas sobre trajetórias escolares bem-sucedidas nas camadas populares são menos frequentes e discute a posição de alguns autores e biografias escolares (PIOTTO, 2008, p. 1-8).

Ana e William foram interrogados sobre o incentivo que receberam da família para a continuidade dos estudos, Ana repetiu o discurso do pai: " [...] Meu pai sempre me dizia que ele passava muitas dificuldades financeiras porque ele não tinha estudo e que, se ele não tinha conquistado melhores empregos e melhores salários, eu deveria estudar para a minha vida ser diferente". (Ana).

Já o estudante explicou que a mãe esteve sempre presente em sua vida escolar, incentivando e conversando, mas não cobrava tanto (William)

Segundo Lahire (1997, p.13-22), não existe reprodução direta entre o desempenho escolar dos alunos e a estrutura familiar, já que é na família que

Revista @rquivo Brasileiro de Educação, Belo Horizonte, vol.1, num.2, jul - dez, 2013. 
se explicam desde os fracassos previsíveis até os sucessos improváveis. São esses os termos usados pelo autor ao explicar situações em que filhos, cujos pais possuem baixo capital cultural, tendem ao fracasso previsível. Os fracassos improváveis advêm de estudantes em condições favoráveis, mas com baixo desempenho escolar. Condições de sucessos escolares improváveis se referem aos alunos com condições desfavoráveis, mas que apresentam desempenho escolar brilhante.

Mesmo não existindo uma reprodução direta entre o desempenho escolar e a estrutura familiar, não podemos negar que a família desempenha um papel fundamental na vida escolar de seus filhos, já que ela é considerada a primeira instituição social formadora do sujeito, potencializando comportamentos e relações sociais. A relação harmoniosa entre família e escola parece assegurar a complementação educacional necessária ao desenvolvimento de crianças e jovens. "A herança familiar é, pois, também uma questão de sentimentos". (LAHIRE, 1997, p.172). O estabelecimento de vínculos é próprio do ser humano e a família, como grupo primário, é o lócus para a concretização desta experiência (GOMES; PEREIRA, 2004, p. 359).

Sobre a influência de algum professor ou da própria escola, ambos apontaram um professor "especial" que os incentivava e repetia inúmeras vezes os conselhos para que eles estudassem e pensassem no que queriam da vida.

"Meu professor não só incentivava, mas ele fazia tudo para a gente gostar da disciplina dele, que era física. Na aula dele, todo mundo ficava quieto e aprendia mesmo!" (William)

"Ana lembrou com carinho algumas palavras que um professor falava em sala: "estudem, façam a diferença... quero vê-los fazendo faculdade! Ele era muito legal, todos gostavam dele" (Ana).

Piotto (2008, p. 1-8) analisa a participação da escola e a presença marcante de um professor na vida escolar dos estudantes, alegando que esse apoio se torna fundamental para a continuidade dos estudos dos jovens.

Revendo as entrevistas, relembramos a importância da motivação na vida de todos nós e, principalmente, na fase escolar de cada estudante, aliada à presença da família, do professor, ou mesmo da escola. Partimos da ideia de que a

Motivação é o aspecto dinâmico da ação: é o que leva o sujeito a agir, ou seja, o que o leva a iniciar uma ação, a orientá-la em função dos objetivos estabelecidos, a decidir o seu prosseguimento e finalização. É, portanto, o processo que mobiliza o organismo para a ação, a partir de uma relação estabelecida entre o ambiente, a necessidade e o objeto de satisfação (RAMOS; PORTO, 2012, p.1).

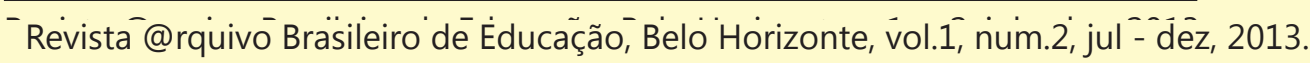


Outra consideração importante refere-se à motivação definida por Piaget: "Ela (a motivação) é o elemento afetivo que impulsiona as estruturas do conhecimento e dá origem a um esforço a ser desenvolvido" (PIAGET, 1974, p.28).

Ana e William foram indagados sobre o diferencial existente nos jovens que conseguem ultrapassar as dificuldades (econômicas, culturais, sociais, etc.) e ingressar numa instituição de nível superior.

Parece que meu interesse é mais focado: quero terminar meu curso, trabalhar, comprar as coisas, casar. Muitos jovens só pensam em balada, bebedeira. Eu me divirto, mas não me esqueço das coisas que tenho que fazer. Acho que tenho mais responsabilidade, sabe? A minha empresa oferece boas oportunidades para quem faz o curso de Marketing, então, eu vou terminar meu curso e vou partir para este outro porque quero melhorar a minha renda (William).

Para Ana, o jovem tem que saber diferenciar as coisas, ter uma análise crítica das situações:

Se assim pode ser ruim para mim, então tenho que ir por outro caminho. Vejo ao meu redor, colegas que não sabem aproveitar as oportunidades. Elas estão fazendo faculdade, mas não se preocupam em aprender mesmo, estudar e participar dos projetos que os professores estão trabalhando. Aí eu pergunto: como é que vai ser o futuro dessas pessoas? Desde pequena eu tinha que ajudar na minha casa, fazer as coisas. Quando eu chegava da escola, eu lavava a louça para a minha mãe. A gente vai aprendendo desde pequena, né? (Ana).

As construções culturais, hábitos e atitudes parecem contribuir com o posicionamento diferenciado entre os sujeitos, na medida em que cada nova geração deverá retomar as heranças do passado e fazer desta apropriação uma questão existencial. As heranças cultural e material são responsáveis pela apreensão das propriedades de seu meio sócio-familiar, mas existe outra dimensão, que ele denomina de imaterial, que são os gostos, as competências, disposições para agir, compreender e julgar, que são próprias, ou como podemos traduzir, são subjetivas e particulares, afirma Lahire (LAHIRE, 2011, p. 20).

\section{Considerações finais}

Com o intuito de pesquisar os fatores que respaldam a atitude do jovem

Revista @rquivo Brasileiro de Educação, Belo Horizonte, vol.1, num.2, jul - dez, 2013. 
estudante de camadas populares que ingressa em universidades públicas a despeito de suas condições de fragilidade e as possíveis interconexões do sucesso escolar com processos subjetivos de sua formação podemos concluir que:

a) A juventude é uma etapa constituída de profundas mudanças qualitativas do pensamento, não se esquecendo das transformações afetivas e sociais, por isso admite-se que o jovem necessita de apoio e incentivos externos. Eles tendem a relacionar o afeto recebido com o desempenho escolar. Piaget explica que "a vida afetiva e a vida cognitiva, mesmo distintas, são inseparáveis" (PIAGET, 2003, p. 16). Ele advertiu sobre o fato de que, apesar de diferentes em sua natureza, a afetividade e a cognição são inseparáveis, indissociadas em todas as ações, quer sensóriomotoras, quer simbólicas. Considerou ainda que a afetividade constitui a força propulsora do desenvolvimento (VIVALDI et al., apud PIAGET 1974;1973).

b) Admite-se uma dimensão subjetiva e particular em estudantes de camadas populares que apresentam sucesso escolar não esperado, considerando que:

A subjetividade é construída nas circunstâncias históricas, culturais e sociais nas quais o indivíduo está inserido e também pelas experiências particulares que ele vivencia no interior dessa cultura que são irrepetíveis e determinam as idiossincrasias e a individualidade de cada um (SALLES, 2005, p.2).

Nesse entendimento, para que o sujeito possa fazer escolhas mais significativas em sua vida, é necessário que a educação e a reflexão sejam elementos pontuais na família e na escola, estimulando a aprendizagem e o conhecimento. Retomemos a definição de Habitus: é o que permite fazer escolhas, tomar decisões, agir adequadamente numa grande variedade de situações sem nem mesmo ter consciência (BOURDIEU, 1990, p. 15-48).

c) 3. As reflexões possibilitam explicar e compreender como os jovens de camadas populares que buscam caminhos desafiadores, ultrapassam barreiras sociais, como o vestibular, imbuídos de uma capacidade interior de enfrentamento, que podemos chamá-la de resiliência, que

Revista @rquivo Brasileiro de Educação, Belo Horizonte, vol.1, num.2, jul - dez, 2013. 
os fazem mais fortes diante de seus projetos de vida.

\begin{abstract}
The present work discusses the entry of low-income youth in the higher education system, emphasizing three distinct moments: the first one, at the end of high school, when the young people are looking for an alternative to prepare themselves for entrance exams; the second one, when they are approved and join a public university; and the third moment, when they are trying to enter the job market after graduating. Therefore, we aim to investigate the factors that underlie the positive attitude of these young people, despite their adverse original conditions. Our methodological approach is a qualitative research, and the data collection instrument used is an interview with two students who fit this profile.
\end{abstract}

Keywords: Education. Low-income youth. Youth motivation.

\title{
Referências
}

BEM, Patrícia Gil do. Ambiente familiar, processos reguladores e resiliência em jovens adolescentes. 128f. 2012. Dissertação (Mestrado)- Universidade Lusófona do Porto, Faculdade de Psicologia, Porto. Disponível em:

<http://recil.grupolusofona.pt/bitstream/handle/10437/3058/Tese_ Patr\%C3\%ADcia\%20do\%20Bem.pdf?sequence=1> Acesso em: 5 ago. 2013.

BONETI, Lindomar Wessler. Formação profissional e emprego num contexto de pobreza: pobre jovem: a condição de acesso ao ensino superior no Brasil. In: BRASIL. Ministério da Saúde. Fundação Oswaldo Cruz. Um olhar sobre o jovem no Brasil. Brasília: Editora do Ministério da Saúde, 2008. 218 p. p. 108. (Serie B. Textos Básicos de Saúde). Disponível em:

<http://bvsms.saude.gov.br/bvs/publicacoes/olhar_sobre_jovem_brasil.pdf>. Acesso em: 4 jul. 2013.

BOURDIEU, Pierre. Coisas ditas. Tradução Cássia R. da Silveira e Denise Moreno Pegorim. São Paulo: Brasiliense, 1990. . 15-48.

CORBUCCI, Paulo Roberto et al. Situação educacional dos jovens brasileiros. In: CASTRO, Jorge Abrahão de.et al. (Org.). Juventude e políticas sociais no Brasil. Brasília: Ipea. 2009.

D'AVILA,G.T. et al. Acesso ao ensino superior e o projeto de "ser alguém" para vestibulandos de um cursinho popular. Psicologia e Sociedade, Florianópolis, v. 23. n. 2. maio/ago, 2011. Disponível em: <www.scielo.br>.

Revista @rquivo Brasileiro de Educação, Belo Horizonte, vol.1, num.2, jul - dez, 2013. 
Acesso em: 06 jul. 2013.

GOMES, Araújo Gomes; PEREIRA, Maria Lúcia Duarte. Família em situação de vulnerabilidade social: uma questão de políticas públicas. 2004, p. 359. Disponível em:<http://www.scielo.br/pdf/csc/v10n2/a13v10n2.pdf>. Acesso em: 03 ago. 2013.

INSTITUTO BRASILEIRO DE GEOGRAFIA E ESTATÍSTICA. Pesquisa Nacional por Amostra de Domicílios 2013: síntese de indicadores 2013. Disponível em:

<http://www.ibge.gov.br/home/estatistica/pesquisas/pesquisa_ resultados.php?id_pesquisa=40> Acesso em: 10 ago. 2013.

INSTITUTO DE PESQUISA ECONÔMICA APLICADA. Revista Desafios do desenvolvimento. Ed. 48. Ano 6. Brasília. 2009. Disponível em: <http://desafios.ipea.gov.br/003/00301009.jsp?ttCD_CHAVE=8719>. Acesso em: 02 fev. 2013. Favor indicar o último link consultado

LAHIRE, Bernard. O sucesso escolar nos meios populares: as razões do improvável. Tradução de Ramon Américo Vasques e Sonia Goldefeder. São Paulo: Ática, 1997.

LAHIRE, Bernard. A transmissão familiar da ordem desigual das coisas. Tradução de Pascoal Carvalho. Sociologia, Revista da Faculdade de Letras da Universidade do Porto, v. XXI, p.13-22, 2011.

LIMA, Maria. Atitudes in psicologia social. In: VALA, Jorge; MONTEIRO Maria B. (Ed.). Título da obra? Lisboa: Fundação Calouste Gulbenkian; 1993. p. 167-199.

PIAGET, Jean. Aprendizagem e conhecimento. Tradução Equipe da Livraria Freitas Bastos. Rio de Janeiro: Freitas Bastos, 1974.

PIAGET, Jean. Problemas de psicologia genética. São Paulo: Forense, 1973.

PIOTTO, Débora Cristina. Trajetórias escolares prolongadas nas camadas populares. Caderno Pesquisa, São Paulo, v. 38, nº. 135, set./ dez., 2008.

Disponível em: <http://.www.scielo.br/scielo.php?script=sci_arttext\&pi d=S0100-15742008000300008 >. Acesso em: 13 jul. 2013.

PROGRAMA DAS NAÇÕES UNIDAS PARA O DESENVOLVIMENTO. Atlas do Desenvolvimento Humano no Brasil 2013. Disponível em: <http://www. pnud.org.br/arquivos/fs5-educacao.pdf>. Acesso em: 30 jul. 2013.

RAMOS, Lízia. PORTO, Amélia. Textos educacionais: motivação e incentivo no processo de aprendizagem. 19 jun. 2012. Disponível em:

Revista @rquivo Brasileiro de Educação, Belo Horizonte, vol.1, num.2, jul - dez, 2013. 
<http://portoconsultoriaetreinamento.blogspot.com.br/2012/06/ motivacao-e-incentivo-no-processo-de.html>. Acesso em: 9 ago. 2013.

RAUPP, Marco Antônio. Educação brasileira exige medidas excepcionais, diz presidente da SBPC. Disponível em: <http://www. sbpcnet.org.br>. Acesso em: 12 jun.2013.

EDUCAÇÃO brasileira exige medidas excepcionais, diz presidente da SBPC. Olhardireto. 25 ago. 2010 . Disponível em: < http://www. sbpcnet.org.br>. Acesso em: 12 jun.2013.

REY, González. O outro no desenvolvimento: diálogos para a pesquisa e a prática profissional em psicologia. SIMÃO, Lívia Mathias; MARTINEZ, Albertina Mitjáns (Org.). O outro no desenvolvimento humano: diálogos para a pesquisa e a prática profissional em psicologia. São Paulo, SP: Thomson, 2004. Disponível em: <http://books.google.com.br> Acesso em: 02 ago. 2013.

SALLES, Leila Maria Ferreira. Infância e adolescência na sociedade contemporânea: alguns apontamentos. Estudos de Psicologia, Campinas, v.22, no.1 jan./mar., 2005. Disponível em: <http:// www.scielo.br/scielo.php?script=sci_arttext\&pid=S0103166X2005000100005> Acesso em: 03 jul. 2013.

SILVA, Hélia Maria Alves da. Resiliência nos jovens: relações familiares e auto-conceito competência. 2009. Tese (Doutorado)- Universidade do Algarve. Faculdade de Ciências Sociais e Humanas. Disponível em: < https://sapientia.ualg.pt/handle/10400.1/367?mode=full >. Acesso em: 8 ago. 2013.

\section{UNIVERSIDADE FEDERAL DE JUIZ DE FORA. Curso pré-universitário} popular da UFJF. Disponível em: <www.cursinho.ufjf.br>. Acesso em: 15 jul. 2013.

VIVALDI, Flávia Maria de Campos et al. Sentimentos sobre a Escola Presentes em Estudantes com e sem Histórico de Fracasso. Revista eletrônica de psicologia e epistemologia genéticas. Vol 4 nº. 1 - jan-jul/2012. Disponível em:<http://www2.marilia.unesp.br/revistas/index.php/scheme> Acesso em: 4 ago. 2013.

WHITAKER, Dulce Consuelo Andreatta; ONOFRE, Silvana Aparecida. Representações sociais em formação sobre os vestibulares dos estudantes de um cursinho comunitário na zona rural. Revista Brasileira Orientação Profissional, São Paulo, v.7, nº. 1, jun. 2006.

WHITAKER, Dulce Consuelo Andreatta; ONOFRE, Silvana Aparecida. Da invenção do vestibular aos cursinhos populares: um desafio para 
Letícia Couto Bicalho, Wânia Maria Araújo, Vanessa Belisário

a orientação profissional. Revista Brasileira Orientação Profissional, São Paulo, v. 11, n 2, p.3, dez., 2010. 